\title{
Integralidade e Humanização em Contextos Educativos: a Experiência do Curso de Graduação em Saúde Coletiva para a Promoção da Saúde nas Escolas
}

\author{
Parreira, Clélia Maria de Sousa Ferreira; Escalda, Patrícia Maria Fonseca; Rodovalho, \\ Giovanna Brunelli \\ Universidade de Brasília - Faculdade de Ceilândia — cleliaparreira@unb.br
}

Introdução: Existem diversas questões que afetam fortemente a saúde de crianças em idade escolar e que estão relacionadas à intensificação da violência, da exclusão, da marginalização, da intolerância e da discriminação - quer seja por razões étnicas, religiosas ou de gênero - sobretudo quando direcionadas a grupos vulneráveis. Fomentar a cultura de paz e práticas solidárias em ambientes escolares passa a ser, então, uma ação efetiva de promoção da saúde que traz contribuições para a garantia dos direitos humanos e para a humanização nas relações interpessoais. Fomentar o exercício da tolerância e a prática do diálogo em contextos e ambientes formativos não é uma responsabilidade exclusiva do setor educacional. a inserção dessa temática na formação de novos profissionais de saúde tem sido buscada cada vez mais nas instituições de ensino superior por ser considerada uma forma estratégica de tratar aspectos relacionados ao princípio da integralidade em saúde e à humanização do cuidado, e que tem se mostrado capaz de ampliar o olhar de estudantes de graduação sobre condicionantes e determinantes sociais da saúde de grande expressão em tempos atuais, especialmente aqueles relacionados ao fenômeno da violência e suas implicações para o comprometimento do bem-estar e da qualidade de vida de crianças e adolescentes. Objetivos: Levar estudantes de graduação da área de saúde a se apropriarem do conceito de integralidade e de humanização em saúde por meio do desenvolvimento de propostas de ação educativa direcionadas a estudantes de escolas públicas - urbanas e rurais - integrantes do Programa Saúde na Escola. a experiência pretende possibilitar o desvelamento das realidades e das condições de vida dos escolares, sobretudo no que diz respeito à interface entre violência e saúde e às possibilidades de problematizar e discutir, no contexto da formação acadêmica, as transformações necessárias ao alcance da humanização do cuidado e da atenção à saúde. Métodos: a experiência tem sido desenvolvida semestralmente, desde 2011, no âmbito de uma disciplina obrigatória do curso de graduação em saúde coletiva cuja natureza, predominantemente prática, tem favorecido a construção de uma abordagem problematizadora e o uso de métodos ativos de ensino-aprendizagem. Os graduandos se tornam responsáveis pelo desenvolvimento de conteúdos e proposição de dinâmicas mais apropriadas aos perfis dos escolares. Resultados: Os resultados têm sido referidos pelos estudantes e pela própria coordenação do Programa Saúde na Escola (PSE) local como uma ação potente para apropriação dos conceitos de integralidade e humanização em saúde e para o fortalecimento da parceria entre a universidade e as redes de ensino e de saúde. Conclusões: a experiência tem possibilitado aos estudantes de graduação uma compreensão acerca da complexidade da saúde e da singularidade do cuidado em saúde, e se constituído um mecanismo de avaliação das ações de educação em saúde realizadas no contexto escolar.

Parreira, Clélia Maria de Sousa Ferreira; Escalda, Patrícia Maria Fonseca; Rodovalho, Giovanna Brunelli. Integralidade e Humanização em Contextos Educativos: a Experiência do Curso de Graduação em Saúde Coletiva para a Promoção da Saúde nas Escolas. In: Anais do Congresso Internacional de Humanidades \& Humanização em Saúde [= Blucher Medical Proceedings, num.2, vol.1]. São Paulo: Editora Blucher, 2014. ISSN 2357-7282

DOI 10.5151/medpro-cihhs-10795 